\title{
Antimicrobial Resistance Patterns and Plasmid Profiles of Methicillin Resistant Staphylococcus aureus Isolated from Clinical Samples
}

\author{
Gaurav Agrahari ${ }^{1}$, Amrit Koirala ${ }^{1}$, Roshan Thapa ${ }^{1}$, Mahesh Kumar Chaudhary ${ }^{2}$ and \\ Reshma Tuladhar ${ }^{*}$ \\ ${ }^{1}$ Central Department of Microbiology, Tribhuvan University, Kirtipur, Nepal, \\ ${ }^{2}$ KIST Medical College, Imadol, Kathmandu, Nepal,
}

\begin{abstract}
Methicillin-resistant Staphylococcus aureus (MRSA), showing resistance to several antibiotics is a global health problem associated with considerable mortality and morbidity. Antibiotic susceptibility test is a commonly used method to characterize MRSA in epidemiologic studies. Additionally, plasmid profile has been reported to be useful in tracing the epidemiology of antibiotic resistance. This research was conducted to determine the antimicrobial resistance patterns and plasmid profiles of MRSA isolated from clinical samples at KIST Medical College, Imadol, Kathmandu, Nepal. All the clinical specimens sent to the laboratory were processed by standard microbiological techniques and antibiotic susceptibility testing was done by the modified Kirby Bauer disc diffusion method. Further, plasmid profiling was done by Alkaline-lysis method. A total of $27(38.02 \%)$ MRSA were isolated from 71 S. aureus positive samples. MRSA showed the highest resistance towards penicillin $(92.60 \%)$ and ampicillin (92.60\%). In contrast, high levels of sensitivity were shown towards vancomycin $(85.19 \%)$ and tetracycline $(85.19 \%)$. Out of 27 MRSA positive samples, single plasmids were isolated from only 6 (22.22\%) MRSA isolates. Antibiograms alone are inadequate to accomplish the characterization of MRSA during epidemiological studies. However, plasmid profile analysis in conjunction with the antibiotic susceptibility pattern is valuable in the epidemiological investigation of MRSA, and for reducing MRSA prevalence and treatment cost.
\end{abstract}

Keywords: Staphylococcus aureus, antibiotic resistance, methicillin resistance S. aureus, plasmid

${ }^{*}$ Corresponding Author

E-mail: resutu@gmail.com

\section{Introduction}

Methicillin-resistant Staphylococcus aureus (MRSA) was first reported in 1961, within a year of methicillin introduction [1]. Since then, MRSA strains have spread among hospitals and disseminated worldwide. Being recognized as a prominent nosocomial pathogen, in the past few decades MRSA has emerged outside of healthcare settings, spreading in the community $[2,3]$. These community-associated MRSA strains have also been shown to be the cause of healthcare-associated infections [4]. Due to an increase in MRSA infection, the rate of morbidity and mortality has increased along with the increase in health care costs.

In various countries, the prevalence of MRSA has varied from hospital to hospital. Indeed, Asia accounts for the highest prevalence rates of healthcare-associated methicillin-resistant $S$. aureus (HA-MRSA) and community-associated methicillin-resistant $S$. aureus (CA-MRSA) in the world. The Majority of hospitals in Asia are endemic for multidrug-resistant MRSA (MDRMRSA), with an estimated proportion of $28 \%$ (in Hong Kong and Indonesia) to $>70 \%$ (in Korea) among all clinical $S$. aureus isolates in the early 2010s [5]. In the United States, MRSA infection is the second major cause of death among people after AIDS per year and is estimated to cause more infections than the other diseases combined [6]. In large United States hospitals (500 or more beds), about $40 \%$ of S. aureus infections are methicillin-resistant and are increasing continuously [7]. In the context of Nepal, various research and studies showed great variations in the prevalence of MRSA 
ranging from $11-50 \%$ [8-13]. Overuse or misuse of antibiotics may be the common reason for the rapid increase in the frequency of MRSA strains as well as MDR-MRSA [14]. Lack of hygienic practices of the medical personnel in hospitals or health care centers and lack of isolation room for the known patients already infected with MRSA strains in health care centers, etc. are the other probable reasons for the increase in MRSA infections [15].

The best understood mobile genetic elements are plasmids, which have been widely studied in epidemiological surveillance of MRSA outbreaks and in tracing antibiotic resistance [16]. It is currently suggested that more than $90 \%$ of MRSA strains carry plasmids while numerous studies have supported that the genetic exchange of plasmids containing antibiotic-resistant genes between bacteria plays an important role in the evolution of multidrugresistance [17-19]. In various epidemiological studies, antibiograms and plasmid profiles are commonly used to characterize MRSA. However, to achieve differentiation, antibiograms are frequently inadequate. Plasmid profile is more instructive and has been reported to be a useful tool in tracing the epidemiology of antibiotic resistance. This study was therefore, conducted to analyze the discriminatory power of plasmid profile analysis in conjunction with antibiogram in differentiating different strains of MRSA and antibiotic resistance patterns and resistance plasmids of MRSA isolated from clinical samples.

\section{Materials and Methods}

This cross-sectional study was conducted at KIST Medical College, Imadol, Kathmandu, Nepal, from May 2014 to November 2014. The study comprises 2044 clinically ill, both indoor and outdoor patients which include children, adult and old of both sexes, aged between one month to ninety years who visited KIST Medical College, Imadol, Kathmandu. All the clinical specimens such as pus, urine, blood, sputum and body fluids were collected in strictly sterile, leak-proof, dry containers which were free from all traces of disinfectants. The sample specimens were collected by medical officers or as per the instruction by the medical officers before the use of antibiotics, and then immediately transferred to microbiology laboratory. The samples taken to the laboratory were processed as quickly as possible. Staphylococci obtained from different clinical specimens were studied for antimicrobial sensitivity pattern, and the MRSA obtained were subjected to plasmid profiling by the Alkaline-lysis method. The identification of the organism was based on standard laboratory criteria (growth in blood agar and McConkey agar media for $24-48$ hours at $37^{\circ} \mathrm{C}$, colonial morphology, Gram staining, catalase test, oxidase test, and coagulase test) [20]. After differentiation based on coagulase, the isolates were examined for the antimicrobial sensitivity pattern. The organisms were screened for MRSA using cefoxitin disc diffusion test. The Plasmid profile of MRSA was done by alkaline lysis method in Central Department of Microbiology, T.U., Kirtipur, Nepal.

\section{Isolation of bacterial plasmid DNA by Alkaline-SDS Lysis}

Plasmid DNA was isolated from MRSA according to Sambrook \& Russel [21]. MRSA isolates were sub-cultured in Luria-Bertani broth at $37^{\circ} \mathrm{C}$ and $3 \mathrm{ml}$ of the overnight culture was subjected to plasmid DNA extraction by centrifugation at $5000 \mathrm{rpm}$ for $5 \mathrm{~min}$. After washing in Tris-ethylene diamine tetraacetic acid (EDTA) buffer (10mM Tris, 1mM EDTA, $\mathrm{pH}$ 8.0, TE), the pellet was added to the freshly prepared mixture of $\mathrm{NaOH}$ and SDS (1:1), to which potassium acetate was added. The microfuge tube was inversely mixed and centrifuged at 13,000 rpm for 10 minutes. The supernatant was transferred into a new microfuge tube with adding Phenol: Chloroform (1:1) and centrifuged at 13,000 rpm for 10 minutes. The upper aqueous phase was collected in a clean microfuge tube to which Chloroform was added and centrifuged at $13,000 \mathrm{rpm}$ for 10 minutes. The supernatant was then transferred into a new microfuge tube and cold 95\% ethanol was added to precipitate bacterial DNA. The pellet was washed with $70 \%$ ethanol and dissolved in $50 \mu \mathrm{l}$ of TE buffer. 
Table 1: Staphylococcal growth from various clinical specimens. Staphylococci were isolated from different clinical samples following standard microbiological techniques. The staphylococcal isolates were screened for S. aureus and CoNS by the coagulase test. S. aureus, Staphylococcus aureus; CoNS, coagulase-negative $S$. aureus.

\begin{tabular}{|c|c|c|c|c|c|c|}
\hline \multirow{2}{*}{$\begin{array}{c}\text { Type of } \\
\text { organism }\end{array}$} & \multicolumn{5}{|c|}{ Types of clinical sample } & \multirow[b]{2}{*}{ Total No. } \\
\hline & $\begin{array}{c}\text { Blood } \\
\text { No }(\%)\end{array}$ & $\begin{array}{c}\text { Urine } \\
\text { No }(\%)\end{array}$ & $\begin{array}{l}\text { Sputum } \\
\text { No }(\%)\end{array}$ & $\begin{array}{c}\text { Pus } \\
\text { No }(\%)\end{array}$ & $\begin{array}{c}\text { Body fluids } \\
\text { No }(\%)\end{array}$ & \\
\hline S. aureus & $23(32.4)$ & $16(22.5)$ & $5(7)$ & $22(31)$ & $5(7)$ & 71 \\
\hline CoNS & 14 (51.9) & $9(33.3)$ & $1(3.7)$ & 3 (11.1) & 0 & 27 \\
\hline Total & $37(37.8)$ & $25(25.5)$ & $6(6.1)$ & $25(25.5)$ & $5(5.1)$ & 98 \\
\hline
\end{tabular}

\section{Preparation of agarose gel}

Agarose gel of 1 percent was prepared by melting 1 gm agarose in $100 \mathrm{ml}$ of diluted TAE buffer using a microwave oven. The molten agarose was allowed to cool to about $50^{\circ} \mathrm{C}$ and $50 \mu$ l ethidium bromide $(1 \mathrm{mg} / \mathrm{ml})$ was added and mixed and was immediately poured into gel tray and the comb was placed. After solidification of the gel, the comb was removed. The gel was placed in a horizontal electrophoresis apparatus filled with TAE buffer.

\section{Loading and electrophoresis of the sample}

Each $5 \mu \mathrm{l}$ of isolated Plasmid DNA was mixed with $1 \mu \mathrm{l}$ of $6 \mathrm{X}$ gel loading buffer. The mixture was slowly loaded into the well using disposable micropipette tips. A marker of $1 \mathrm{~Kb}$ molecular weight was loaded in one well to determine the size of the Plasmid DNA. Electrophoresis was carried out at 100 volts for 1 hour.

\section{Visualization of the gel}

The amplified products of the study samples were visualized by using UV trans-illuminator. The gel was photographed by a digital camera and transferred data to the computer for further documentation .

\section{Results \\ Identification and distribution of MRSA}

In this study different clinical samples were taken from out-patients and various wards of the KIST Medical College, Imadol, Kathmandu. For the identification of staphylococci, standard microbiological procedures were followed. This involves the morphological appearance of the isolated colony, staining reactions and biochemical properties. Each of the organisms was first isolated in pure form. Then colony morphology was noted, which was followed by Gram's staining and biochemical tests. The detailed biochemical, cultural and staining techniques are mentioned in the supplementary section. Among all the clinical specimens processed during the study period, 414 specimens showed positive growth among which 98 were isolated and identified as staphylococci by standard microbiological technique. The staphylococcal isolates were screened for $S$. aureus and coagulase-negative staphylococci by the coagulase test. Out of 98 positive staphylococcal growths from different clinical specimens, 71 isolates were found to be coagulase-positive and were defined as $S$. aureus (Table 1).

Out of 71 isolates of S. aureus, 27(38.02\%) isolates were resistant to cefoxitin ( $<22 \mathrm{~mm})$ and were defined as MRSA. Out of 27 MRSA isolates, highest number of MRSA was isolated from pus sample $(n=8)$ followed by urine $(n=8)$ and blood $(n=7)$. However, only 2 MRSA was isolated from sputum specimens and only one from body fluids (Figure 1).

\section{Antibiotic susceptibility pattern of MRSA isolates}

We next determined the antibiotic susceptibility pattern of MRSA isolates. Here, we found that vancomycin and tetracycline $(74.07 \%)$ were the most effective drugs whereas ampicillin $(92.60 \%)$ and penicillin $(92.60 \%)$ were least sensitive to MRSA isolates (Figure 2). 


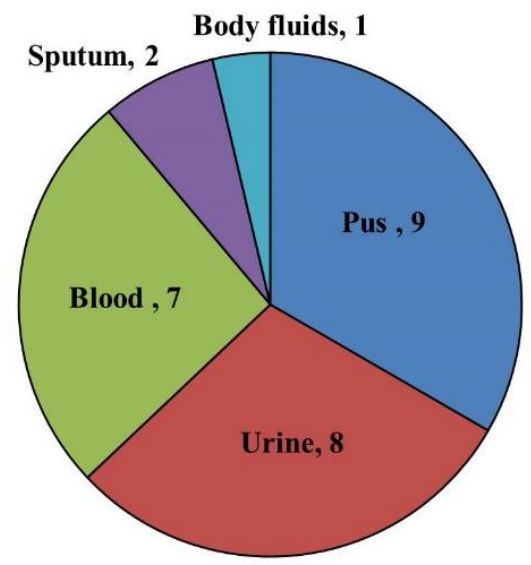

Number of MRSA in different clinical specimens

Figure 1: Distribution of MRSA in different clinical specimens. S. aureus were isolated from different clinical samples by standard microbiological techniques and were identified as MRSA by testing with cefoxitin discs having a zone of inhibition less than $22 \mathrm{~mm}$. The number in the pie-chart indicates the number of MRSA isolated from different clinical specimens. S. aureus, Staphylococcus aureus; MRSA, methicillin-resistant $S$. aureus

\section{Plasmid Profiling of MRSA}

Twenty-seven isolates of MRSA isolated from various clinical samples were screened for plasmids. Out of these, 21 strains $(77.77 \%)$ lacked any plasmid and 6 strains $(22.22 \%)$ were detected with only one plasmid (Figure 3). The isolated plasmid and molecular weight of the plasmid can be visualized in the agarose gel shown in Figure 3. The plasmid profile of MRSA and plasmid profile with antimicrobial resistance patterns are shown in Table 2.

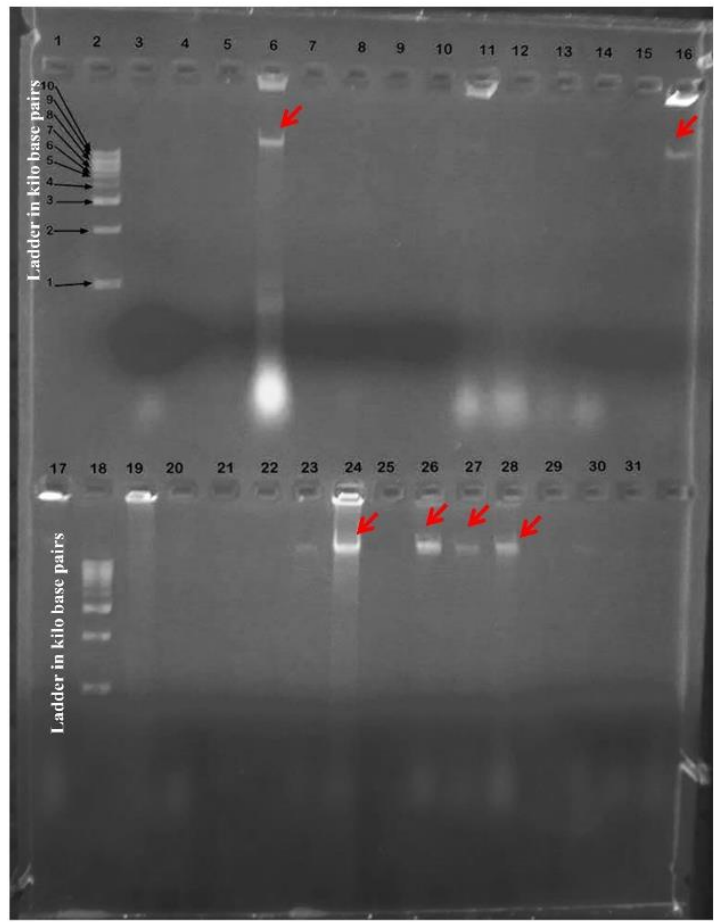

Figure 3: Plasmid profile of MRSA. Plasmids were isolated by the alkaline-lysis method and were run in $1 \%$ agarose gel. Lane 1 and lane 18 were loaded with $1 \mathrm{~kb}$ ladder, lane $6,16,24,26$, 27 and 28 shows the positive samples with plasmid and are indicated by the red arrow.

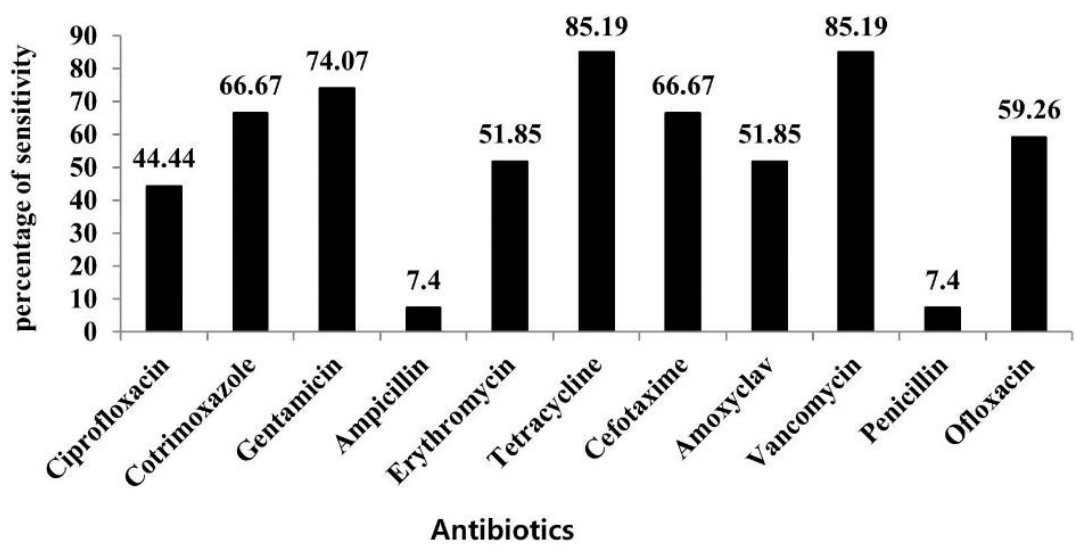

Figure 2: Antibiotic sensitivity patterns of MRSA isolates. Antibiotics sensitivity of MRSA was determined by the Kirby-Bauer disc diffusion method. The number in the graph indicates the percentage of the susceptibility of MRSA towards various tested antibiotics. 
Table 2. Plasmid profiles and antimicrobial resistance of MRSA. Plasmids from MRSA were isolated by Alkaline-lysis method and antibiotic susceptibility patterns were determined by modified Kirby-Bauer disc diffusion method. Amp, ampicillin; AMC, amoxyclav; Cx, cefoxitin; COT, cotrimoxazole; Cip, ciprofloxacin; E, erythromycin; Ctx, cefotaxime; Gen, gentamycin; Of, ofloxacin; P, penicillin; VA, vancomycin.

\begin{tabular}{|c|l|l|}
\hline Isolates & Plasmid size (bp) & Drug resistant \\
\hline 1 & $>10,000$ & $\begin{array}{l}\text { E, Cx, P, AMC, Amp, } \\
\text { Of }\end{array}$ \\
\hline 2 & $>10,000$ & $\begin{array}{l}\text { COT, Gen, Ctx, E, C } \\
\text { x, P, Amp }\end{array}$ \\
\hline 3 & $>10,000$ & $\begin{array}{l}\text { Cip, COT, Ctx, Amp, } \\
\text { E, Cx, P }\end{array}$ \\
\hline 4 & $>10,000$ & $\begin{array}{l}\text { Ctx, Amp, E, Cx, P, } \\
\text { VA }\end{array}$ \\
\hline 5 & $>10,000$ & Ctx, Amp, E, Cx, P, \\
\hline 6 & $>10,000$ & Cx, Amp, P \\
\hline
\end{tabular}

\section{Discussion}

In this study, cefoxitin disk was used for the detection of methicillin-resistant $S$. aureus. Oxacillin can also be used but the cefoxitin disk diffusion method is more effective in detecting hetero-resistant MRSA. Cefoxitin is also an inducer of the mecA gene hence suitable for detecting hetero-resistant MRSA. Furthermore, it gives a clearer endpoint and is easier to read than tests with oxacillin [22-24].

The present study revealed that the prevalence of MRSA was $38.02 \%$ from the total isolated $S$. aureus. The result of the present study correlates with the findings of the study conducted by Rajaduraipandi et al [25] where the prevalence of MRSA was 37.9\% and with Sanjana et al [26] where $39.9 \%$ MRSA was isolated from different clinical samples.

In developing countries like Nepal, screening of antibiotic susceptibility pattern of MRSA is a great tool for effective treatment and cost minimization. In this study, we determined the antibiotic susceptibility pattern of MRSA through the disc diffusion method. Here, we found that $92.60 \%$ of MRSA isolates were resistant to conventional drugs such as penicillin and ampicillin. Whereas, vancomycin and tetracycline were found to be the most effective drug as $85.19 \%$ of MRSA isolates showed sensitivity pattern. Thus, tetracycline can be considered as an alternative for vancomycin in the case of vancomycin resistant S. aureus.

Plasmid profile has been reported as one of the techniques for typing MRSA [27]. Here, 27 MRSA isolates were subjected to plasmid isolation by Alkaline-lysis method. Alkalinelysis in combination with the detergent SDS has been used for more than 20 years to isolate plasmid DNA from E. coli [28]. Exposure of bacterial isolates to strongly anionic detergent at high $\mathrm{pH}$ opens the cell wall, denatures chromosomal DNA and proteins and releases plasmid DNA into the supernatant. In this study, out of 27 MRSA isolates only 6 (22.22\%) had plasmids. Plasmid profile analysis appears to be of very low discriminatory capacity in the investigation of MRSA epidemiology because of the non-detection of plasmids in the majority of the MRSA strains. This has been reported by Terry et al [29] and Ugbugo et al [30]. All plasmid-carrying strains harbored a single plasmid. This result was compatible with the study of Maithem et al [31] in which all the isolates harbored single plasmid. The acquisition of methicillin resistance is through a highly mobile genetic element, staphylococcal cassette chromosome (SCCmec) that carries mecA gene and confers methicillin resistance. A Study by Caddick et al [32] showed that the presence of plasmid DNA is involved in the acquisition of multi-drug resistance. However, there exists no significant correlation between plasmid DNA and multidrug-MRSA. This could be the possible reason for the low isolation of plasmid in our study. The molecular weights of the isolated plasmids were found to be more than ten thousand base pairs. This result was compatible with the study of Badger- Emeka et al [33] where all the isolates harbored plasmid with molecular weight ranging from 4969- 12130 bp. All the MRSA strains which harbored the plasmid showed resistance towards $\beta$-lactam antibiotics such as cefoxitin, penicillin, and ampicillin. This was also similar to BadgerEmeka et al [33] where plasmid harbored strains had more resistance towards $\beta$-lactam antibiotics. Thus, it might be concluded that the 
resistance of MRSA towards $\beta$ - lactam antibiotics was plasmid-mediated.

The detection of mecA gene or penicillin-binding protein $2 \mathrm{a}$ is considered as a more reliable and confirmatory method for identifying MRSA [34]. Furthermore, plasmid profiling along with antibiotic susceptibility patters are considered as a useful method for epidemiological studies and to design antibiotic policies and effective control measures [27, 31]. In this study, we determined the prevalence of MRSA in different clinical specimens along with their antibiotic susceptibility pattern and plasmid profiling. However, the determination of mecA gene should be done to confirm MRSA isolates and are limited in this study. The result of this study concluded that there is a great need of regular surveillance in order to monitor resistance patterns and minimize the increase of antibioticresistant micro-organisms.

\section{Acknowledgements}

I am really very delighted and want to express my deep thankfulness to all the staff of Central Department of Microbiology (CDM) and KIST hospital for their continuous support and help during my entire lab work. Last but not the least, I want to deeply thank my family, my roommates and my friends for providing me support, guidance and encouragement.

\section{Conflict of interest}

The authors declare no conflict of interest.

\section{Author contributions}

Gaurav Agrahari contributed to the conceptualization, formal analysis, investigation, methodology, visualization, and writing; Amrit Koirala, Roshan Thapa, and Mahesh Kumar Chaudhary played a supporting role in the investigation, methodology, and writing; Reshma Tuladhar contributed to conceptualization, supervision, validation, and writing.

\section{References}

1. Lowy FD: Antimicrobial resistance: the example of Staphylococcus aureus. J Clin Invest. 2003 111:1265-1273.

2. Chambers HF: The changing epidemiology of Staphylococcus aureus? Emerg Infect Dis. 2001 7:178-182.
3. Klevens RM, Edwards JR, Tenover FC, McDonald LC, Horan T, Gaynes R: Changes in the epidemiology of methicillin-resistant Staphylococcus aureus in intensive care units in US hospitals, 1992-2003. Clin Infect Dis. 2006 42:389-391.

4. Otter JA, French GL: Community-associated meticillin-resistant Staphylococcus aureus strains as a cause of healthcare-associated infection. J Hosp Infect. 2011 79:189-193.

5. Chen CJ, Huang YC: New epidemiology of Staphylococcus aureus infection in Asia. Clin Microbiol Inf. 2014 20(7):605-623.

6. Red Book: Report of the Committee on Infectious Diseases. 26th ed. Elk Grove Village, IL: American Academy of Pediatrics; 2003: 561-572.

7. Klevens RM, Morrision MA, Nadle J, Petit S, Gershman K, Ray S: Invasive methicillinresistant Staphylococcus aureus infections in the United States. JAMA. 2007 298: 17631771.

8. Lamichhane R, Adhikari RP, Sherchand JB: Study of Methicillin Resistant Staphylococcus aureus (MRSA) isolated from different clinical samples. M. Sc. Dissertation. Central Department of Microbiology, Tribhuvan University, Kirtipur, Kathmandu, Nepal; 1999.

9. Rajbhandari R: Prevalence and Antibiotic Sensitivity Pattern of Methicillin Resistant Staphylococcus aureus (MRSA) in Bir Hospital. M. Sc. Dissertation. Central Department of Microbiology, Tribhuvan University, Kirtipur, Kathmandu, Nepal; 2002.

10. Kumari N, Mohapatra TM, Singh YI: Prevalence of Methicillin Resistant Staphylococcus aureus (MRSA) in a Tertiary Care Hospital in Eastern Nepal. JNMA 2008, 47: 53-56.

11. Thapa KB: Methicillin Resistant Staphylococcus aureus (MRSA) in clinical samples and nasal screening for MRSA carriage among healthy carriers in hospital setting. M.Sc. Dissertation. Central Department of Microbiology, Tribhuwan University; 2011.

12. Pandey S, Raja MS, Bhatta CP: Prevalence and Antibiotic Sensitivity Pattern of Methicillin-Resistant Staphylococcus aureus in Kathmandu Medical College, Teaching Hospital. JIOM. 2012 34:13-17.

13. Mukhiya RK, Shrestha A, Rai SK, Panta K, Singh RN, Rai G, et al: Prevalence of Methicillin-Resistant Staphylococcus aureus in Hospitals of Kathmandu Valley. NJST. 2012 13:185-190.

14. Centers for Disease Control and Prevention, Office of Infectious Disease Antibiotic resistance threats in the United States, 2013. Available 
http://www.cdc.gov/drugresistance/threat -report-2013. Accessed January 28, 2015.

15. Pittet D, Hugonnet S, Harbarth S, Mourouga $\mathrm{P}$, Sauvan V, Touveneau $\mathrm{S}$, et al: Effectiveness of a hospital-wide programme to improve compliance with hand hygiene. Lancet. 2000 356:1307-1312.

16. Al-Mohana AM, Al-Charrakh AH, Nasir FH, Al-Kudhairy MK: Community-acquired methicillin-resistant Staphylococcus aureus carrying mecA and Panton-Valentine leukocidin (PVL) genes isolated from the holy shrine in Najaf, Iraq. Afr J Bacteriol Res. 2012 4(2):15-23.

17. Coia JE, Noor-Hussain I, Platt DJ: Plasmid profiles and restriction enzyme fragmentation patterns of plasmids of methicillin-sensitive and methicillinresistant isolates of Staphylococcus aureus from hospital and the community. J Med Microbiol. 1988 27: 271-276.

18. Morton TM, Johnston JL, Patterson J, Archer GL: Characterization of a conjugative staphylococcal mupirocin resistance plasmid. Antimicrob Agents Chemother. 1995 39: 1272-1280.

19. Paulsen IT, Brown MH, Skurray RA: Characterization of the earliest known Staphylococcus aureus plasmid encoding a multidrug efflux system. J Bacteriol. 1998 180: 3477-3479.

20. Collee JF, Fraser AG, Marmion BO, Simmons A: Staphylococcus: cluster forming Gram positive cocci. Mcckie and McCartney Practical Medical Microbiology $14^{\text {th }}$ edn. Churchil Livingstone, USA. 2006, 245-62.

21. Sambrook J, Russell DW: Molecular cloning. A Laboratory Manual. 3rd edition. CSHL press 2001, 131-134.

22. Broekema NM, Van TT, Monson TA, Marshall SA, Warshauer DM: Comparison of cefoxitin and oxacillin disk diffusion methods for detection of mecA-mediated resistance in Staphylococcus aureus in a large-scale study. J clinic microbial. 2009 47(1):217-219.

23. Felten A, Grandry B, Lagrange PH, Casin I: Evaluation of three techniques for detection of low-level methicillin-resistant Staphylococcus aureus (MRSA): a disk diffusion method with cefoxitin and moxalactam, the Vitek 2 system, and the MRSA-screen latex agglutination test. J clinic microbial. 2002 40(8):2766-2771.

24. Mimica MJ, Berezin EN, Carvalho RL, Mimica IM, Mimica LM, Sáfadi MA, et al: Detection of methicillin resistance in Staphylococcus aureus isolated from pediatric patients: is the cefoxitin disk diffusion test accurate enough? Braz J Infect Dis. 2007 11(4):415-417.
25. Rajaduraipandi K, Mani KR, Panneerselvam K, Mani M, Bhaskar M, Manikandan P: Prevalence and antimicrobial susceptibility pattern of methicillin resistant Staphylococcus aureus: A multicentre study. Ind j med microbial. 2006 24(1): 34-38.

26. Sanjana RK, Shah R, Chaudhary N, Singh YI: Prevalence and antimicrobial susceptibility pattern of Methicillin-resistant Staphylococcus aureus (MRSA) in CMSteaching hospital: a preliminary report. $J$ College Medical Sci-Nepal. 20106 (1): 1-6.

27. Tayfour MA, Eris FN, Alanazi AR: Comparison of antibiotic susceptibility tests, plasmid profiles and restriction enzymes analysis of plasmid DNA of methicillin susceptible and resistant Staphylococcus aureus strains isolated from intensive care units. Saudi Med J. 2005, 26(1): 57-63.

28. Birnboim HC, Doly J: A rapid alkaline extraction procedure for screening recombinant Plasmid DNA. Nucleic Acids Res. 1979, 7:1513-1523.

29. Terry Alli OA, Akinloye O, Rowley DA, Butcher PD: A comparative assessment of ribosomal DNA polymorphisms in methicillin resistant Staphylococcus aureus (MRSA) epidemiology. Afr J Biomed Res. 2002 10: $117-125$.

30. Ugbogu OC, Akinsade AK, Nwokocha KO, Ahuama OC: Plasmid Profile of Methicillin Resistant Staphylococcus aureus isolates from University Students. Nigerian J Microbiol 2011 25: 2363-2368.

31. Maithem A, Al-Hamdani MA, Hamad IG: Study of plasmid profile, susceptibility patterns of clinical Staphylococcus aureus isolated from patients with otitis media in Basrah. J Basrah res. 2012 38: 79-89.

32. Caddick JM, Hilton AC, Rollason J, Lambert PA, Worthington T, Elliott TS: Molecular analysis of methicillin-resistant Staphylococcus aureus reveals an absence of plasmid DNA in multidrug-resistant isolates. FEMS Immunol Med Microbiol. 2005 44(3):297-302.

33. Badger- Emeka LI, Emeka PM, Dibua UME: Plasmid profile of multi antibiotic resistant Stahylococcus aureus isolated from diabetic wounds from patients at Nsukka, Southeastern, Nigeria. Afr J biotech. 2014 13(43): 4148-4152.

34. Boyce JM: Methicillin-resistant Staphylococcus aureus in hospitals and long-term care facilities: microbiology, epidemiology, and preventive measures. Infec Control Hosp Epidemiol 1992 13(12):725737 